$16^{\circ}$ USIHC - Congresso Internacional de Ergonomia e Usabilidade de Interfaces Humano Computador

CINAHPA | 2017 - Congresso Internacional de Ambientes Hipermídia para Aprendizagem.

\section{ARTEFATOS PARA O DESENHO E A ESCRITA: UM ESTUDO EM DESIGN DE PRODUTO}

\section{ARTIFACTS FOR DRAWING AND WRITING: A STUDY IN PRODUCT DESIGN}

\author{
Juliana Fonsêca de Queiroz Marcelino ${ }^{1}$, M.Sc., doutoranda em Design \\ Anna Verenna de Arêdes Oliveira ${ }^{2}$, acadêmica de Design \\ Raquel Costa Albuquerque ${ }^{3}$, D.Sc. \\ Laura Bezerra Martins ${ }^{4}$, D.Sc. \\ Ana Karina Pessoa da Silva Cabral ${ }^{5}$, M.Sc., doutoranda em Design
}

(1) Universidade Federal de Pernambuco (UFPE)

e-mail: julifons@yahoo.com.br

(2) UFPE

e-mail:verenna.aredes@gmail.com

(3) UFPE

e-mail: raquel.albuquerque@terra.com.br

(4) UFPE

e-mail: bmartins.laura@gmail.com

(5) UFPE

e-mail: anakarinapessoa@gmail.com

Palavras-chave: Adaptação, Design de produto, Grafismo

Este estudo, qualitativo e de corte transversal, é resultado de um PIBIC e de um projeto de extensão. O objeto de estudo são artefatos que auxiliem ou possibilitem a atividade da escrita para crianças com as habilidades motoras comprometidas. Assim, teve-se como objetivo analisar o design destes produtos no cenário atual do mercado, na rede municipal de ensino e em pesquisas sobre o tema. Foi realizado um levantamento de artefatos no Mercado e em Escolas Municipais e, posteriormente, foi desenvolvida uma análise do design dos produtos, com base em Löbach, Munari e Bonsiepe, incluindo avaliação da percepção estética dos artefatos por 3 estudantes de Design. Os resultados refletem a dificuldade de acesso aos produtos na Cidade do Recife, a ausência de informações na especificação dos produtos, porém, a categorização dos produtos foi uma experiência inovadora, diante da escassez de respaldo teórico para a análise dos produtos do caráter da pesquisa.

Keywords: Adaptation, Product design, Graphism.

This qualitative and cross-sectional study is the result of a PIBIC and an extension project. The object of study are artifacts that aid or enable the writing activity for children with impaired motor skills. Thus, the objective was to analyze the design of these products in the current market scenario, in the municipal education network and in research on the subject. A survey of artifacts was carried out in the Market and in Municipal Schools, and a product design analysis was developed based on Löbach, Munari and Bonsiepe, including evaluation of the aesthetic perception of the artifacts by 3 Design students. The results reflect the difficulty of accessing the products in the City of Recife, the lack of information in the specification of the products, however, the categorization of the products was an innovative experience due to the lack of theoretical support for the analysis of the products of the research character. 


\section{$16^{\circ}$ \\ ERGODESIGN USIHC CINAHPA}

\section{Introdução}

Dentre as diversas atividades que representam a iniciação efetiva no processo de desenvolvimento lúdico de uma criança, a grafia toma forma imprescindível. Conforme Cassis e Francisqueti (2006), o desenho é uma produção da criança por meio da qual ela expressa situações reais. $\mathrm{O}$ desenho será realizado com qualquer instrumento como uma extensão do seu corpo.

No entanto, algumas crianças, quando apresentam sequela devido à Paralisia Cerebral (PC), deficiência que compromete a programação e execução adequada dos movimentos voluntários, precisam de algum tipo de adaptação para desenvolver grafismos (MARCELINO; MARTINS, 2015).

O mercado oferece atualmente artefatos voltados ao grafismo, sejam eles de baixa ou alta tecnologia, ou seja, mais simples ou mais sofisticados. A tecnologia, seja qual for, deve agir como suporte para uma sociedade que funciona de modo fluido e igualitário. De acordo com Sassaki (2016), os artefatos não devem agir como barreira às atividades cotidianas do indivíduo. Desse modo, o Design age diretamente nessa ponte de acessibilidade uma vez que diz respeito ao desenvolvimento de produtos e de ambientes para serem usados por todas as pessoas, na maior extensão possível, prevê as situações cotidianas e norteia o desenvolvimento e a avaliação de ambientes, produtos e serviços mais abertos às diferenças.

No desenvolvimento de produtos, apesar de todo um esforço, nem sempre é possível contemplar de forma absoluta todos os usuários, como propõe os princípios do Design Universal, descritos por Connel et al (1997). Faz-se necessário, muitas vezes, desenvolver produtos para uma população específica, ou até mesmo para uma pessoa específica, situação na qual a participação do usuário torna-se imprescindível.

No campo do Design, dentre outros estudiosos descritos por Marcelino, Araújo e Martins (2016), Clarkson et al (2003) discutem a Inclusão, a partir da compreensão de que a deficiência resulta do ambiente e das oportunidades ofertadas aos sujeitos. Neste sentido, o designer pode se dedicar a propor soluções especiais e dispositivos assistivos em direção à acessibilidade.

A multidisciplinaridade é fundamental no processo de Tecnologia Assistiva. Para o desenvolvimento de produtos, de um lado, o designer parte da ideia geral do pensar de um produto acessível e do outro, o terapeuta ocupacional avalia, de forma pontual, a relação do desempenho funcional do usuário versus produto, contribuindo no contorno de situações que isoladamente não seriam revertidas apenas pelo design.

Surge, então, a necessidade de ponderar tais ferramentas disponíveis no mercado e sua usabilidade, verificando seu caráter funcional para crianças com deficiência, especialmente no que diz respeito à eficácia na promoção da função de grafismos de modo a auxiliar a área da ergonomia, que busca, por meio de métodos e técnicas, o levantamento de dados para subsidiar o designer no desenvolvimento de produtos, de acordo com Moraes e Mont'alvão (2003).

Assim, o design mostra-se imprescindível para a expressão gráfica da pessoa com deficiência. A justificativa para o estudo parte do princípio de que o design é uma ferramenta que tende a solucionar problemas e apresentar alternativas cada vez mais viáveis aos usuários uma vez que avalia e intervém sobre o ambiente e os artefatos, bem como sobre outras variáveis, para obtenção de melhores resultados na usabilidade. Dentro desse viés, o presente artigo justifica-se e demonstra sua relevância na medida em que busca oferecer subsídios e informações nesse campo, enquadrando-se como pesquisa afim à tese de doutorado em Design em desenvolvimento, intitulada "Eficácia e Eficiência de Produtos Assistivos Nacionais sobre a Grafomotricidade de Crianças com Discinesia".

Este trabalho é resultado de um PIBIC e de um projeto de extensão, desenvolvidos entre os anos de 2015 e 2016, e objetiva analisar o design de produtos para o desenho ou escrita comercializados
Realização:

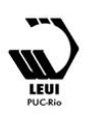




\section{$16^{\circ}$ \\ ERGODESIGN USIHC CINAHPA}

no cenário atual do mercado, na rede pública de ensino e em pesquisas sobre o tema.

\section{Método}

\subsection{Tipos e locais de estudo}

Estudo qualitativo, de corte transversal.

\subsection{Participantes da pesquisa}

Participaram 149 profissionais do Atendimento Educacional Especializado (AEE), sendo 148 da formação e um da Escola que foi visitada, além de 3 estudantes que avaliaram esteticamente os produtos levantados.

\subsection{Período do Estudo}

Do segundo semestre de 2015 ao segundo semestre de 2016.

\subsection{Coleta de dados}

Os dados foram coletados por meio de revisão de literatura, sites, lojas físicas no Recife, visita escolar e notas de campo provenientes da formação de educadores.

\subsubsection{Sobre a revisão de literatura}

Foi avaliada a disponibilidade de material sobre adaptações da atividade de grafismo, estudos para pessoas com deficiência, a relação do grafismo com o aprendizado, tecnologia assistiva, terapia ocupacional, entre outras publicações pertinentes, buscando estabelecer a ligação entre esses temas e o design. Foi essencial adentrar determinadas etapas do desenvolvimento de produtos, que classificam e analisam artefatos e objetos em relação a suas características e peculiaridades.

\subsubsection{Pesquisa de mercado}

Envolveu a identificação e análise de produtos para desenho e escrita disponíveis no mercado e na rede pública de ensino, num processo de avaliação dos artefatos, bem como sua preparação para atender pessoas com deficiência. Nesse sentido, levantouse, em sites e lojas físicas, artefatos que foram $16^{\circ}$ Ergodesign - Congresso Internacional de Ergonomia e Usabilidade de Interfaces Humano Tecnológica: Produto, Informações Ambientes Construídos e Transporte

$16^{\circ}$ USIHC - Congresso Internacional de Ergonomia e Usabilidade de Interfaces Humano Computador

CINAHPA | 2017 - Congresso Internacional de Ambientes Hipermídia para Aprendizagem. registrados e catalogados com o padrão: material, fixação ao membro, usabilidade, dimensões, tipo de pega, tipo de forma e variabilidade estética (para os encontrados online) e local encontrados, item e imagem do artefato (para os encontrados em lojas físicas do Recife). Estes foram baseados na descrição de atributos visuais do objeto e suas qualidades (LÖBACH, 2001).

\section{(a) Online}

O processo de levantamento online se deu pela busca inicial em sites nacionais especializados em Terapia Ocupacional, acessibilidade, tecnologia assistiva e temas afins, nos catálogos disponíveis on-line de adaptações até se esgotarem os itens englobados pela pesquisa. Os itens estudados são, especificamente, objetos que adaptem mecanismos para grafismo tais como canetas e lápis. Os dispositivos que, de alguma forma, ao serem acoplados a certos materiais forneçam uma pega mais agradável, diminua tremores ou, até mesmo, que passem a possibilitar o processo de escrita são o foco do estudo.

A fim de coletar maiores informações sobre os artigos, seus nomes foram traduzidos para o inglês visto que a maioria deles é confeccionada e disponibilizada com maiores informações em países norte-americanos, em especial nos Estados Unidos. Depois o mesmo processo de esgotamento e análise dos catálogos on-line foi desenvolvido, agora em sites fora do País, em grande maioria de língua inglesa. Por fim, pesquisas gerais em mecanismos de busca foram realizadas a partir dos descritores: adaptações gráficas, tecnologia assistiva, adaptação para lápis, lápis adaptado, assistive technology, adapted pencil.

Para analisar a compatibilidade com o público alvo, as dimensões dos produtos foram comparadas às medidas da mão infantil (largura e comprimento), com base em Esteves et al (2005), com o objetivo de alcançar a faixa etária adequada dos usuários dos produtos.

\section{(b) Em lojas físicas}

Ocorreu em lojas de equipamentos de reabilitação e em papelarias do Recife. As lojas de reabilitação
Realização:

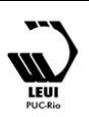




\section{$16^{\circ}$ \\ ERGODESIGN USIHC CINAHPA}

$16^{\circ}$ Ergodesign - Congresso Internacional de Ergonomia e Usabilidade de Interfaces Humano Tecnológica: Produto, Informações Ambientes Construídos e Transporte

$16^{\circ}$ USIHC - Congresso Internacional de Ergonomia e Usabilidade de Interfaces Humano Computador

CINAHPA | 2017 - Congresso Internacional de Ambientes Hipermídia para Aprendizagem. foram consultadas por telefone, quando não foi identificado nenhum artefato. A venda deste tipo de produto somente ocorre por encomenda às distribuidoras que se localizam no Sul e Sudeste, e algumas lojas de reabilitação podem mediar o pedido. A seleção das papelarias a serem analisadas foi realizada a partir do porte do estabelecimento. As de pequeno porte foram deixadas fora da pesquisa, bem como aquelas que apresentam difícil localização no Recife, como em becos e ruelas. A prioridade foi dada àquelas que ficam em avenidas principais e ruas acessíveis da cidade. Foram visitadas, no total, 6 papelarias.

O procedimento de pesquisa nesses locais foi simples: o responsável pela papelaria era questionado se o acervo da loja contava com qualquer tipo de material que pudesse ser acoplado a lápis e canetas a fim de tornar a escrita facilitada, além de que era realizada visita ao setor que poderia conter este tipo de material.

\subsubsection{Rede escolar municipal}

No projeto de extensão "Adaptações para facilitar a grafomotricidade de crianças com sequela de Paralisia Cerebral no ambiente escolar" foi desenvolvida uma formação a profissionais do Atendimento Educacional Especializado da Rede Municipal, que assistem crianças com deficiência no contraturno de aula, numa sala específica denominada Sala de Recursos Multifuncionais (INEP, 2011).

Seguindo os princípios éticos, estes participantes assinaram o Termo de Consentimento Livre e Esclarecido, aprovado pelo Comitê de Ética em Pesquisa Envolvendo Seres Humanos sob registro CAAE 55342916.2.0000.5208. Foram realizadas duas palestras, tendo uma como tema "Paralisia Cerebral" e outra "Adaptadores de Lápis". Nesta segunda, que ocorria logo em seguida à primeira, eram apresentados os artefatos levantados nas etapas anteriores, de pesquisa de mercado, referentes ao PIBIC, e os participantes eram instigados a discutirem sobre o que utilizavam nas Escolas, para que também pudéssemos identificar outros artefatos, com design diferenciado. Foram realizadas notas de campo para posterior análise destes discursos.

Foi também desenvolvida uma visita a uma escola municipal, que ocorreu em um único momento, e visou ao levantamento de artefatos, processo de aquisição e uso no contexto escolar.

\subsubsection{Consulta da percepção estética aos estudantes}

Para a avaliação da percepção estética dos produtos foi realizada uma consulta a 3 estudantes de Design. Eles tiveram acesso às imagens dos artefatos encontrados no mercado, disponibilizadas em documento Word. Assim, as imagens das adaptações foram analisadas com base na escala de Likert. Os participantes escolheram na escala de 5 pontos, o que mais se aproxima de como eles perceberam esteticamente as adaptações, que tinha como opções: desagradável, pouco agradável, neutro, agradável e muito agradável.

\subsection{Análise dos dados}

Foi desenvolvida uma tabela no Excel para lançamento das fontes onde foram encontrados os artefatos, bem como das variáveis estudadas, citadas anteriormente. $\mathrm{O}$ banco de dados contém as imagens dos dispositivos e filmagens da preensão/pega de pessoas no uso dos mesmos. As configurações dos artefatos foram analisadas qualitativamente, conforme suas características, com respaldo da literatura na área de Design do produto e Ergonomia.

As notas de campo resultantes da visita escolar e da discussão durante a formação dos educadores foram analisadas pelo método de Análise do Discurso.

\section{Resultados e Discussão}

No total, o estudo conseguiu compilar 29 adaptações, das quais apenas 2 foram encontradas nas papelarias posteriormente. Os 27 artefatos levantados online foram coletados em 16 sites diferentes -6 nacionais e 10 de fora do País. Porém, apenas as encontradas online obtiveram a análise do design neste estudo, visto que não foram obtidas informações suficientes para as 


\section{$16^{\circ}$ \\ ERGODESIGN USIHC CINAHPA}

encontradas em lojas físicas, bem como em algumas outras encontradas online e nem foram encontradas adaptações de lápis comercializadas na Rede Escolar Municipal.

As Escolas supracitadas não têm acesso a adaptações de lápis comercializadas. Os artefatos que os educadores utilizam são artesanais, confeccionados por eles, em sua maioria, e, de modo geral, com um design simples, que são os "engrossadores", ou seja, proporcionando aumento do diâmetro para a pega do lápis. Os materiais utilizados pelos mesmos para proporcionar este aumento de diâmetro são diversos, tais como fita adesiva, cano PVC, emborrachado, tubos recicláveis e punho de bicicleta.

$\mathrm{O}$ fato acima relatado foi confirmado durante a visita escolar. A Escola Municipal, localizada na Região Metropolitana do Recife, possui um pequeno arsenal adaptado para o público com deficiência. $\mathrm{O}$ espaço atualmente conta com 68 alunos que se utilizam das adaptações, a partir dos 8 anos de idade. O colégio conta com transporte inclusivo, inúmeros jogos educativos, impressora em braile entre outros artigos adaptados. A orientação foi ministrada pela educadora do atendimento educacional especializado, que explicou, na sala de recursos multifuncionais, os artefatos cedidos ao colégio.

Em nível das adaptações para grafismos, a educadora que nos recebeu durante a visita expôs que os alunos tendem a rejeitar objetos que destoam dos utilizados usualmente pelo restante dos colegas. Podemos também levantar a hipótese de que o design de produtos não responde às demandas dos usuários. Dentro dos materiais de tecnologia assistiva do colégio, os que costumavam existir para adaptação dos materiais estudados eram confeccionados pelos próprios professores, mas caíram em desuso devido a pouca resposta dos alunos.

Quanto ao levantamento no Comércio Recifense, foram visitadas 6 papelarias, localizadas respectivamente nas seguintes avenidas e bairros: 1 - Avenida Conde da Boa vista, Boa vista; 2 Avenida Conselheiro Aguiar, Boa viagem; 3 - Rua $16^{\circ}$ Ergodesign - Congresso Internacional de Ergonomia e Usabilidade de Interfaces Humano Tecnológica: Produto, Informações Ambientes Construídos e Transporte

$16^{\circ}$ USIHC - Congresso Internacional de Ergonomia e Usabilidade de Interfaces Humano Computador

CINAHPA | 2017 - Congresso Internacional de Ambientes Hipermídia para Aprendizagem.

velha, Boa vista; 4 - Avenida Caxangá, Madalena; 5 - Avenida Dantas Barreto, Santo Antônio; 6 Avenida Dantas Barreto, Santo Antônio. Adaptações foram encontradas apenas nos estabelecimentos 2 e 3 :

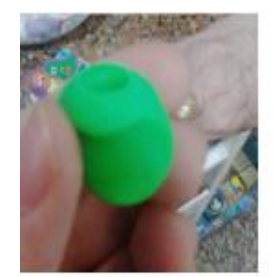

Engrossador anatômico cis

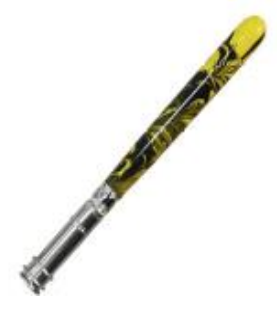

Extensor de lápis Keramik
Seguimos, portanto, com a Análise do Design dos Produtos selecionados, encontrados online.

\subsection{Classificações}

- Levantamento online

Os artefatos encontrados online serão listados no quadro 1 , que identifica o nome e a fonte dos mesmos. As figuras 1 e 2 (abaixo) exemplificam os produtos encontrados. Levando em conta as medidas antropométricas da mão infantil, foi realizada uma análise quanto à possibilidade de uso dos produtos por este público, a partir da comparação das dimensões das adaptações encontradas com a largura e comprimento da mão de pessoas dos sexos masculino e feminino a partir dos sete anos de idade, de acordo com Esteves et al (2005). Desse modo, as seguintes legendas encaixam os artefatos nas respectivas faixas etárias:
A: Sem restrições;
B: A partir dos 11 anos de idade
C: Medidas indisponíveis

É importante ressaltar que a faixa de idade dos usuários foi estipulada apenas por meio da comparação de medidas, não levando em
Realização:

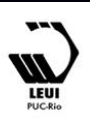




\section{$16^{\circ}$ \\ ERGODESIGN USIHC CINAHPA}

consideração informações como força de preensão e casos extremos, quando as medidas das mãos das crianças não se encaixam nas médias da população. Desse modo, seria necessário o acesso as adaptações para se chegar a informações mais precisas.

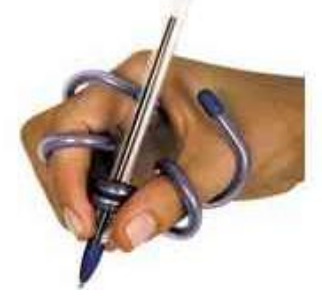

Figura 1 - Artefato 1: Aranha Mola

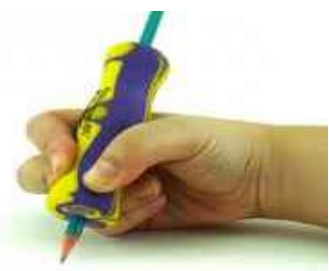

Figura 2 - Artefato 3: Engrossador anatômico

\begin{tabular}{|c|c|}
\hline 1. Aranha mola (B) & \multirow{3}{*}{$\begin{array}{l}\text { Catálogo Nacional de } \\
\text { Produtos de Tecnologia } \\
\text { Assistiva (2015) }\end{array}$} \\
\hline 2. Engrossadores (A) & \\
\hline 3. Engrossador anatômico (A) & \\
\hline $\begin{array}{l}\text { 4. Adaptação bulbo para escrita } \\
\text { (A) }\end{array}$ & \multirow[t]{5}{*}{ MN Suprimentos (2015) } \\
\hline $\begin{array}{l}\text { 5. Adaptação triangular para } \\
\text { escrita (A) }\end{array}$ & \\
\hline $\begin{array}{l}\text { 6. Adaptação crossover para } \\
\text { escrita (A) }\end{array}$ & \\
\hline 7. Auxiliar para escrita slip on (A) & \\
\hline $\begin{array}{l}\text { 8. Prancheta com adaptação } \\
\text { imantada para escrita (A) }\end{array}$ & \\
\hline 9. Lápis garra (A) & $\begin{array}{l}\text { Writing Assistive } \\
\text { Technologies for Reluctan } \\
\text { Writers (2015) }\end{array}$ \\
\hline 10. Lápis escrita firme (A) & $\begin{array}{l}\text { Care Giver Products } \\
(2015)\end{array}$ \\
\hline 11. Eazyhold (A) & EAZYHOLD $^{\mathrm{TM},}$ (2015) \\
\hline 12. Ring writer clip (A) & \multirow[t]{3}{*}{$\begin{array}{l}\text { Maddak Sp Ableware } \\
\text { (2016) }\end{array}$} \\
\hline 13. Arthwiter (B) & \\
\hline 14. Ergowiter (A) & \\
\hline
\end{tabular}

$16^{\circ}$ Ergodesign - Congresso Internacional de Ergonomia e Usabilidade de Interfaces Humano Tecnológica: Produto, Informações Ambientes Construídos e Transporte

$16^{\circ}$ USIHC - Congresso Internacional de Ergonomia e Usabilidade de Interfaces Humano Computador

CINAHPA | 2017 - Congresso Internacional de Ambientes Hipermídia para Aprendizagem.

\begin{tabular}{|c|c|}
\hline $\begin{array}{l}\text { 15. Tira para adaptação de lápis } \\
\text { (A) }\end{array}$ & $\begin{array}{l}\text { Instituto Sabrina Belon } \\
(2016) \\
\text { MN Suprimentos (2016) }\end{array}$ \\
\hline $\begin{array}{l}\text { 16. Tuboform facilitador de } \\
\text { punho e polegar }(\mathrm{C})\end{array}$ & \multirow[t]{3}{*}{$\begin{array}{l}\text { Expansão Laboratório de } \\
\text { Tecnologia Terapêutica } \\
(2016)\end{array}$} \\
\hline 17. Tuboform gama $(\mathrm{C})$ & \\
\hline 18. Tuboform delta (C) & \\
\hline 19. Abilitations egg ohs! (A) & School Especialty (2016) \\
\hline 20. Easy glide writer (A) & $\begin{array}{l}\text { Direct Medical Supply } \\
\text { (2016) }\end{array}$ \\
\hline 21. Adaptação para escrita (C) & Autonomie (2016) \\
\hline $\begin{array}{l}\text { 22. Lápis ergonômico universal } \\
\text { (A) }\end{array}$ & Amazon (2016) \\
\hline 23. Ring pen ultra (A) & My Diffability (2016) \\
\hline 24. Handiwriter (A) & Enasco (2016) \\
\hline 25. Adaptação universal (C) & Autonomie (2016) \\
\hline 26. Ippo coiled pencil grip (A) & Jetpens (2016) \\
\hline 27. Butter grip (A) & $\begin{array}{l}\text { Ark Therapeutic Services } \\
(2016)\end{array}$ \\
\hline
\end{tabular}

Quadro 1: Nome e fonte dos artefatos encontrados

\subsection{Aplicação das categorias:}

- Sobre as categorias

Bonsiepe e Yamada (1982) apontam que "não existe uma classificação coerente do universo dos produtos para pessoas deficientes. Este universo é bastante complexo e contém um grande número de diferentes produtos". Apesar de ser uma referência antiga, ainda encontramos este cenário nos dias de hoje. Baseando-se nisso, foi desenvolvida essa categorização de adaptações, que conta com sistema de análise dos produtos pela ótica do Design.

A primeira parte da classificação conta com conceitos práticos, aplicados de modo objetivo e de caráter pouco flexível, enquanto a segunda permeia categorias mais subjetivas, uma vez que ainda é escasso o material que avalie artefatos da tecnologia assistiva, aqui apresentados a fim fomentar esse processo de classificação mais aprofundada de artigos desse caráter.
Realização:

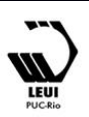




\section{$16^{\circ}$ \\ ERGODESIGN USIHC CINAHPA}

\subsubsection{Parte 1}

- Material:

A especificação do material, presente no artefato, subordina-se a uma premissa no Design de Produtos, que é responsável por determinar as características de um objeto, contribuindo na qualidade de uso e da qualidade estética do produto (GOMES FILHO, 2006). O material interfere tanto no acabamento do produto, como na sua funcionalidade pois, Munari (1981), em sua ficha de análise de produtos, levanta a necessidade de adequação do material ao objeto, mantendo sua função com êxito. Desse modo, procura-se definir nesse tópico o que compõe de forma principal e determinante os artefatos levantados, de acordo com as informações disponibilizadas (ex.: silicone, acrílico, entre outros).

\section{- Fixação ao membro}

Quando se trata de um objeto portátil, Munari (1981) pontua a pormenorização do tipo de manejo como parte importante da análise de um produto. Alguns artefatos são manejados a partir do seu acoplamento à mão/braço, por meio de velcro, correias, alças, entre outros, mantendo o artigo sempre associado ao usuário mesmo sem processo voluntário. Outros, no entanto, permitem a livre pega, sem nada que fixe diretamente seus membros ao objeto. Desse modo os artefatos serão classificados como.

a) fixos

b) não fixos

- Finalidade

Se o artigo funciona apenas para adaptação de artefatos para grafismo ou possui outras funções

a) exclusivo para grafismos

b) finalidade múltipla (podendo adaptar outros artefatos, como talheres) $16^{\circ}$ Ergodesign - Congresso Internacional de Ergonomia e Usabilidade de Interfaces Humano Tecnológica: Produto, Informações Ambientes Construídos e Transporte

$16^{\circ}$ USIHC - Congresso Internacional de Ergonomia e Usabilidade de Interfaces Humano Computador

CINAHPA | 2017 - Congresso Internacional de Ambientes Hipermídia para Aprendizagem.

\section{- Dimensões}

Medidas relativas aos tamanhos do objeto.

\begin{tabular}{|c|c|c|c|c|}
\hline Artefato & Material & $\begin{array}{l}\text { Fixação } \\
\text { ao } \\
\text { membro }\end{array}$ & Usabilidade & $\begin{array}{l}\text { Dimensões } \\
\text { (aproximadas) }\end{array}$ \\
\hline 1 & $\begin{array}{l}\text { Silicone e } \\
\text { carbono } \\
\text { especial } \\
\text { flexível }\end{array}$ & Fixo & $\begin{array}{l}\text { Exclusivo } \\
\text { grafismo }\end{array}$ & $\begin{array}{l}9 \mathrm{~cm} \times 7,5 \mathrm{~cm} \\
\times 3 \mathrm{~cm}\end{array}$ \\
\hline 2 & $\begin{array}{l}\text { Polietileno } \\
\text { Expandido }\end{array}$ & $\begin{array}{l}\text { Não } \\
\text { Fixo }\end{array}$ & $\begin{array}{l}\text { Usabilidade } \\
\text { múltipla }\end{array}$ & $6,2 \times 1,4 \mathrm{~cm}$ \\
\hline 3 & Espuma & $\begin{array}{l}\text { Não } \\
\text { Fixo }\end{array}$ & $\begin{array}{l}\text { Usabilidade } \\
\text { múltipla }\end{array}$ & $20,59 \times 3,0 \mathrm{~cm}$ \\
\hline 4 & Plástico & $\begin{array}{l}\text { Não } \\
\text { Fixo }\end{array}$ & $\begin{array}{l}\text { Exclusivo } \\
\text { grafismo }\end{array}$ & $5,8 \times 1,2 \mathrm{~cm}$ \\
\hline 5 & Plástico & $\begin{array}{l}\text { Não } \\
\text { Fixo }\end{array}$ & $\begin{array}{l}\text { Exclusivo } \\
\text { grafismo }\end{array}$ & $3,5 \times 1,7 \mathrm{~cm}$ \\
\hline 6 & Plástico & $\begin{array}{l}\text { Não } \\
\text { Fixo }\end{array}$ & $\begin{array}{l}\text { Exclusivo } \\
\text { grafismo }\end{array}$ & $2,3 \times 2,5 \mathrm{~cm}$ \\
\hline 7 & Plástico & Fixo & $\begin{array}{l}\text { Exclusivo } \\
\text { grafismo }\end{array}$ & $\begin{array}{l}\text { Variadas; de } \\
6,4 \text { a } 11 \mathrm{~cm}\end{array}$ \\
\hline 8 & Látex & $\begin{array}{l}\text { Não } \\
\text { Fixo }\end{array}$ & $\begin{array}{l}\text { Exclusivo } \\
\text { grafismo }\end{array}$ & $3,81 \times 2,28 \mathrm{~cm}$ \\
\hline 9 & $\begin{array}{l}\text { Metal e } \\
\text { imã }\end{array}$ & $\begin{array}{l}\text { Não } \\
\text { Fixo }\end{array}$ & $\begin{array}{l}\text { Exclusivo } \\
\text { grafismo }\end{array}$ & $30 \times 45 \mathrm{~cm}$ \\
\hline 10 & Látex & $\begin{array}{l}\text { Não } \\
\text { Fixo }\end{array}$ & $\begin{array}{l}\text { Exclusivo } \\
\text { grafismo }\end{array}$ & $2 \times 6 \times 7 \mathrm{~cm}$ \\
\hline 11 & Látex & Fixo & $\begin{array}{l}\text { Usabilidade } \\
\text { múltipla }\end{array}$ & $\begin{array}{l}\text { Tamanhos } \\
\text { variados, de } \\
10,16 \mathrm{~cm} \mathrm{a} \\
19,05 \mathrm{~cm}\end{array}$ \\
\hline 12 & Polietileno & Fixo & $\begin{array}{l}\text { Usabilidade } \\
\text { múltipla }\end{array}$ & $\begin{array}{l}\text { Diâmetro: (P) } \\
1,47 \mathrm{~cm} ;(\mathrm{M}) \\
1,85 \mathrm{~cm} ;(\mathrm{G}) \\
2,21 \mathrm{~cm}\end{array}$ \\
\hline 13 & $\begin{array}{l}\text { Indispo- } \\
\text { nível }\end{array}$ & $\begin{array}{l}\text { Não } \\
\text { Fixo }\end{array}$ & $\begin{array}{l}\text { Usabilidade } \\
\text { múltipla }\end{array}$ & $\begin{array}{l}\text { Diâmetro: } 7,6 \\
\mathrm{~cm} \text {; Buraco: } \\
1,6 \mathrm{~cm}\end{array}$ \\
\hline 14 & $\begin{array}{l}\text { Espuma e } \\
\text { plástico }\end{array}$ & $\begin{array}{l}\text { Não } \\
\text { Fixo }\end{array}$ & $\begin{array}{l}\text { Exclusivo } \\
\text { grafismo }\end{array}$ & $7 \times 6 \times 1,5 \mathrm{~cm}$ \\
\hline 15 & $\begin{array}{l}\text { Velcro e } \\
\text { plástico }\end{array}$ & Fixo & $\begin{array}{l}\text { Exclusivo } \\
\text { grafismo }\end{array}$ & Indisponíveis \\
\hline 16 & Arame de & Fixo & Usabilidade & Indisponíveis \\
\hline
\end{tabular}


$16^{\circ}$ USIHC - Congresso Internacional de Ergonomia e Usabilidade de CINAHPA Interfaces Humano Computador

CINAHPA | 2017 - Congresso Internacional de Ambientes Hipermídia para Aprendizagem.

\begin{tabular}{|c|c|c|c|c|}
\hline & $\begin{array}{l}\text { aço } \\
\text { revestido } \\
\text { de } \\
\text { silicone, } \\
\text { espuma de } \\
\text { etil vinil } \\
\text { acetato, } \\
\text { velcro e } \\
\text { polietileno }\end{array}$ & & múltipla & \\
\hline 17 & $\begin{array}{l}\text { Arame de } \\
\text { aço } \\
\text { revestido } \\
\text { de } \\
\text { silicone, } \\
\text { espuma de } \\
\text { etil vinil } \\
\text { acetato, } \\
\text { velcro e } \\
\text { polietileno }\end{array}$ & Fixo & $\begin{array}{l}\text { Usabilidade } \\
\text { múltipla }\end{array}$ & Indisponíveis \\
\hline 18 & $\begin{array}{l}\text { Arame de } \\
\text { aço } \\
\text { revestido } \\
\text { de } \\
\text { silicone, } \\
\text { espuma de } \\
\text { etil vinil } \\
\text { acetato, } \\
\text { velcro e } \\
\text { polietileno }\end{array}$ & Não fixo & $\begin{array}{l}\text { Usabilidade } \\
\text { múltipla }\end{array}$ & Indisponíveis \\
\hline 19 & Borracha & Fixo & $\begin{array}{l}\text { Exclusivo } \\
\text { grafismo }\end{array}$ & $\begin{array}{l}1,3 \times 5.7 \times 3.8 \\
\mathrm{~cm}\end{array}$ \\
\hline 20 & $\begin{array}{l}\text { Espuma } \\
\text { PVC }\end{array}$ & Fixo & $\begin{array}{l}\text { Exclusivo } \\
\text { grafismo }\end{array}$ & $\begin{array}{l}5,08 \mathrm{~cm} \mathrm{x} \\
17,78 \mathrm{~cm} \mathrm{x} \\
12,7 \mathrm{~cm}\end{array}$ \\
\hline 21 & $\begin{array}{l}\text { Neoprene } \\
\circledR\end{array}$ & Fixo & $\begin{array}{l}\text { Exclusivo } \\
\text { grafismo }\end{array}$ & Indisponível \\
\hline 22 & Sílica gel & Não fixo & $\begin{array}{l}\text { Exclusivo } \\
\text { grafismo }\end{array}$ & $\begin{array}{l}1 \mathrm{~cm} \times 7,8 \mathrm{~cm} \\
\times 9,9 \mathrm{~cm}\end{array}$ \\
\hline 23 & Plástico & Fixo & $\begin{array}{l}\text { Usabilidade } \\
\text { múltipla }\end{array}$ & $\begin{array}{l}10 \mathrm{~cm} \mathrm{x} 3,75 \\
\mathrm{~cm}\end{array}$ \\
\hline 24 & $\begin{array}{l}\text { Algodão, } \\
\text { cetim e } \\
\text { plástico }\end{array}$ & Fixo & $\begin{array}{l}\text { Exclusivo } \\
\text { grafismo }\end{array}$ & $\begin{array}{l}8 \mathrm{~cm} \times 8 \mathrm{~cm} \mathrm{x} \\
1,2 \mathrm{~cm}\end{array}$ \\
\hline 25 & Neoprene & Fixo & $\begin{array}{l}\text { Usabilidade } \\
\text { múltipla }\end{array}$ & Indisponível \\
\hline 26 & $\begin{array}{l}\text { Indispo- } \\
\text { nível }\end{array}$ & Não fixo & $\begin{array}{l}\text { Exclusivo } \\
\text { grafismo }\end{array}$ & $\begin{array}{l}4,7 \mathrm{~cm} \\
\text { (comprimento); } \\
0,9 \mathrm{~cm} \text { de } \\
\text { diâmetro }\end{array}$ \\
\hline 27 & Plástico & Não fixo & $\begin{array}{l}\text { Exclusivo } \\
\text { grafismo }\end{array}$ & $\begin{array}{l}2,5 \mathrm{~cm} \\
\text { (diâmetro) }\end{array}$ \\
\hline
\end{tabular}

\subsubsection{Parte 2}

- Tipo de pega:

Há várias formas de projetar os membros quando um objeto está sendo utilizado. Aqui, o modo como a mão é condicionada ao interagir com a adaptação está sendo observado, se o usuário maneja o artefato deixando-as livres ou condicionando uma pega específica. Ainda em sua ficha de análise de produtos, Munari (1981) aponta a necessidade de verificação da ergonomia do objeto em relação ao seu manuseio e conforto do usuário. Subdividiu-se, então, o tipo de pega em duas seções:

a) Mão livre: a pega pode direcionar, mas não condiciona uma posição específica da mão;

b) Mão posicionada: o artefato induz uma posição pouco variável.

\section{- Variabilidade estética}

Por se tratarem de artefatos adaptados que facilitam a execução da escrita, a maioria dos objetos catalogados assumem majoritariamente uma função prática, porém, como discorre Löbach (2001, p. 67), "todo produto industrial tem uma aparência sensorialmente perceptível". De acordo com Gomes Filho (2006), a função estética é "o aspecto psicológico da percepção multissensorial que tem como atributo principal a fruição da beleza, do prazer e do bem-estar contemplativo". Ela tem, portanto, participação na concepção dos artefatos analisados, por ser um fator importante para o usuário do produto. Abaixo encontra-se o quadro com análise do tipo de pega e resultado da consulta aos 3 estudantes de design quanto à percepção estética.

\begin{tabular}{|l|l|l|}
\hline Artefato & Tipo de pega & Variabilidade estética \\
\hline 1 & $\begin{array}{l}\text { Mão } \\
\text { posicionada }\end{array}$ & $\begin{array}{l}\text { Participante 1 - Desagradável } \\
\text { Participante 2 - Desagradável } \\
\text { Participante 3 - Pouco agradável }\end{array}$ \\
\hline 2 & Mão livre & $\begin{array}{l}\text { Participante 1 - Neutro } \\
\text { Participante 2 - Neutro } \\
\text { Participante 3 - Neutro }\end{array}$ \\
\hline
\end{tabular}

Quadro 2: Categorização parte 1 

Interfaces Humano Tecnológica: Produto, Informações Ambientes

$16^{\circ}$ USIHC - Congresso Internacional de Ergonomia e Usabilidade de Interfaces Humano Computador

CINAHPA | 2017 - Congresso Internacional de Ambientes Hipermídia para Aprendizagem.

\begin{tabular}{|c|c|c|}
\hline 3 & Mão livre & $\begin{array}{l}\text { Participante } 1 \text { - Neutro } \\
\text { Participante } 2 \text { - Desagradável } \\
\text { Participante } 3 \text { - Neutro }\end{array}$ \\
\hline 4 & Mão livre & $\begin{array}{l}\text { Participante } 1 \text { - Agradável } \\
\text { Participante } 2 \text { - Agradável } \\
\text { Participante } 3 \text { - Agradável }\end{array}$ \\
\hline 5 & Mão livre & $\begin{array}{l}\text { Participante } 1 \text { - Agradável } \\
\text { Participante } 2 \text { - Muito agradável } \\
\text { Participante } 3 \text { - Agradável }\end{array}$ \\
\hline 6 & $\begin{array}{l}\text { Mão } \\
\text { posicionada }\end{array}$ & $\begin{array}{l}\text { Participante } 1 \text { - Agradável } \\
\text { Participante } 2 \text { - Pouco agradável } \\
\text { Participante } 3 \text { - Agradável }\end{array}$ \\
\hline 7 & Mão livre & $\begin{array}{l}\text { Participante } 1 \text { - Neutro } \\
\text { Participante } 2 \text { - Desagradável } \\
\text { Participante } 3 \text { - Neutro }\end{array}$ \\
\hline 8 & Mão livre & $\begin{array}{l}\text { Participante } 1 \text { - Muito agradável } \\
\text { Participante } 2 \text { - Neutro } \\
\text { Participante } 3 \text { - Agradável }\end{array}$ \\
\hline 9 & $\begin{array}{l}\text { Mão } \\
\text { posicionada }\end{array}$ & $\begin{array}{l}\text { Participante } 1 \text { - Agradável } \\
\text { Participante } 2 \text { - Pouco agradável } \\
\text { Participante } 3 \text { - Neutro }\end{array}$ \\
\hline 10 & $\begin{array}{l}\text { Mão } \\
\text { posicionada }\end{array}$ & $\begin{array}{l}\text { Participante } 1 \text { - Pouco agradável } \\
\text { Participante } 2 \text { - Pouco agradável } \\
\text { Participante } 3 \text { - Neutro }\end{array}$ \\
\hline 11 & $\begin{array}{l}\text { Mão } \\
\text { posicionada }\end{array}$ & $\begin{array}{l}\text { Participante } 1 \text { - Neutro } \\
\text { Participante } 2 \text { - Desagradável } \\
\text { Participante } 3 \text { - Agradável }\end{array}$ \\
\hline 12 & $\begin{array}{l}\text { Mão } \\
\text { posicionada }\end{array}$ & $\begin{array}{l}\text { Participante } 1 \text { - Neutro } \\
\text { Participante } 2 \text { - Neutro } \\
\text { Participante } 3 \text { - Agradável }\end{array}$ \\
\hline 13 & $\begin{array}{l}\text { Mão } \\
\text { posicionada }\end{array}$ & $\begin{array}{l}\text { Participante } 1 \text { - Desagradável } \\
\text { Participante } 2 \text { - Desagradável } \\
\text { Participante } 3 \text { - Desagradável }\end{array}$ \\
\hline 14 & $\begin{array}{l}\text { Mão } \\
\text { posicionada }\end{array}$ & $\begin{array}{l}\text { Participante } 1 \text { - Neutro } \\
\text { Participante } 2 \text { - Desagradável } \\
\text { Participante } 3 \text { - Neutro }\end{array}$ \\
\hline 15 & $\begin{array}{l}\text { Mão } \\
\text { posicionada }\end{array}$ & $\begin{array}{l}\text { Participante } 1 \text { - Neutro } \\
\text { Participante } 2 \text { - Desagradável } \\
\text { Participante } 3 \text { - Desagradável }\end{array}$ \\
\hline 16 & $\begin{array}{l}\text { Mão } \\
\text { posicionada }\end{array}$ & $\begin{array}{l}\text { Participante } 1 \text { - Neutro } \\
\text { Participante } 2 \text { - Desagradável } \\
\text { Participante } 3 \text { - Neutro }\end{array}$ \\
\hline 17 & $\begin{array}{l}\text { Mão } \\
\text { posicionada }\end{array}$ & $\begin{array}{l}\text { Participante } 1 \text { - Neutro } \\
\text { Participante } 2 \text { - Desagradável } \\
\text { Participante } 3 \text { - Desagradável }\end{array}$ \\
\hline 18 & $\begin{array}{l}\text { Mão } \\
\text { posicionada }\end{array}$ & $\begin{array}{l}\text { Participante } 1 \text { - Muito agradável } \\
\text { Participante } 2 \text { - Pouco agradável } \\
\text { Participante } 3 \text { - Neutro }\end{array}$ \\
\hline
\end{tabular}

\begin{tabular}{|l|l|l|}
\hline 19 & Mão livre & $\begin{array}{l}\text { Participante 1 - Agradável } \\
\text { Participante 2 - Pouco agradável } \\
\text { Participante 3 - Agradável }\end{array}$ \\
\hline 20 & Mão livre & $\begin{array}{l}\text { Participante 1 - Neutro } \\
\text { Participante 2 - Neutro } \\
\text { Participante 3 - Neutro }\end{array}$ \\
\hline 21 & $\begin{array}{l}\text { Mão } \\
\text { posicionada }\end{array}$ & $\begin{array}{l}\text { Participante 1 - Neutro } \\
\text { Participante 2 - Desagradável } \\
\text { Participante 3 - Neutro }\end{array}$ \\
\hline 22 & $\begin{array}{l}\text { Mão } \\
\text { posicionada }\end{array}$ & $\begin{array}{l}\text { Participante 1 - Agradável } \\
\text { Participante 2 - Pouco agradável } \\
\text { Participante 3 - Neutro }\end{array}$ \\
\hline 25 & $\begin{array}{l}\text { Mão } \\
\text { posicionada }\end{array}$ & $\begin{array}{l}\text { Participante 1 - Agradável } \\
\text { Participante 2 - Pouco agradável } \\
\text { Participante 3 - Desagradável }\end{array}$ \\
\hline posicionada & $\begin{array}{l}\text { Mão } \\
\text { posicionada }\end{array}$ & $\begin{array}{l}\text { Participante 2 - Desagradável } \\
\text { Participante 1 - Pouco agradável } \\
\text { Participante 3 - Neutro }\end{array}$ \\
\hline 24 & $\begin{array}{l}\text { Partipante 3 - Neutro } \\
\text { Participante 1 - Agradável } \\
\text { Participante 2 - Agradável } \\
\text { Participante 3 - Muito agradável }\end{array}$ \\
\hline Participante 3 - Neutro \\
\hline 25
\end{tabular}

Quadro 3: categorização parte 2

Observa-se que os participantes tenderam a opiniões similares, ocorrendo grande discrepância em poucos dos artefatos analisados. Percebeu-se que a receptividade estética dos produtos, quando negativa, deu-se muito em parte pela pouca familiaridade dos participantes com os itens apresentados, que causaram certa estranheza. Fator importante a se considerar na avaliação da usabilidade, pois muitas vezes faz-se necessário conceder um tempo de aproximação do usuário ao artefato proporcionando familiaridade. Os artigos que, por unanimidade, foram avaliados como agradáveis pelos participantes se aproximam dos engrossadores encontrados em canetas e lapiseiras comumente comercializados. 


\section{$16^{\circ}$ \\ ERGODESIGN USIHC CINAHPA}

\section{Conclusões}

Como era esperado, o mercado recifense respalda de modo insatisfatório pessoas com deficiência motora. Pesquisando fora do mercado especializado, pouquíssimos estabelecimentos disponibilizam artigos para esse público que pouco se vê representado.

O processo da análise sincrônica resultante da pesquisa online se mostrou dificultada pela lacuna existente nas informações disponíveis aos usuários em relação aos produtos ofertados, os quais, em sua maioria, apresentavam apenas o valor do artigo em questão. Desse modo, muitas adaptações relevantes foram descartadas por insuficiência de informações e a análise não pode se aprofundar por outros campos, como usabilidade e ergonomia somado também ao fato de não ter sido possível a interação entre produtos - pesquisador. Grande parte dos produtos catalogados encontrados nas lojas virtuais são produzidos e vendidos por lojas estadunidenses, e o contato com os fornecedores foi dificultado por esse fator.

As papelarias do Recife têm um arsenal muito limitado em relação a adaptações até mesmo em estabelecimentos que comercializam materiais voltados para os usuários com deficiência.

Pela caraterística multidisciplinar deste estudo, perpassando os conhecimentos do Design, da Terapia Ocupacional e da Tecnologia Assistiva, foi necessário adentrar campos com os quais o design não está tão familiarizado, como pega, preensão, adaptações, órteses, e medidas relativas a mão do usuário. A categorização dos produtos foi uma experiência inovadora, diante da escassez de respaldo teórico para a análise dos produtos do caráter da pesquisa.

O grafismo, tão relevante na comunicação, é dificultado quando não existe uma perspectiva de mecanismos que abarquem o maior número de usuários possível. Iniciar um processo de análise desses produtos torna mais transparentes as soluções e as lacunas que ainda precisam ser preenchidas num cenário inclusivo. $16^{\circ}$ Ergodesign - Congresso Internacional de Ergonomia e Usabilidade de Interfaces Humano Tecnológica: Produto, Informações Ambientes Construídos e Transporte

$16^{\circ}$ USIHC - Congresso Internacional de Ergonomia e Usabilidade de Interfaces Humano Computador

CINAHPA | 2017 - Congresso Internacional de Ambientes Hipermídia para Aprendizagem.

\section{Bibliografia}

Amazon. Disponível em <http://www.amazon. com/Pencil-Universal-Ergonomic-WritingColors/dp/B00U5KWEBS/ref=pd_sim_328_11?ie $=\mathrm{UTF} 8 \& \mathrm{dpID}=31 \mathrm{qtpMutoj} L \& \mathrm{dpSrc}=$ sims $\&$ preST $=$ AC_UL160_SR160\%2C160_\&refRID=16PM5 XTFH8RMMGYJE0ZF>. Acesso em 11 de abril de 2016.

Ark therapeutic services. Disponível em <http://www.arktherapeutic.com/arks-butter-gripcombo/>. Acesso em 22 de maio de 2016.

Autonomie. Disponível em

<http://www.autonomie.com.br/?p=produto\&idpro duto $=44>. ;<$ http://www.autonomie.com.br/?p=pro duto\&idproduto $=43>$ Acesso em 20 de agosto de 2016.

BONSIEPE, G.; YAMADA, T. Design Industrial Para Pessoas Deficientes. Brasília: $\mathrm{CNPq}-$ Coordenação Editorial, 1982.

Care Giver Products. Disponível em < http://www.caregiverproducts.com/steady-writepen.html >. Acesso em 07 de outubro de 2015

CASSIS;, L.; FRANCISQUETTI., A. A. Avaliação da Imagem em crianças portadoras de paralisia cerebral através da história de "Alice no pais das maravilhas." Arquivos brasileiros de paralisia cerebral, São Paulo, v. 15, n. 89/90, 2006.

Catálogo nacional de produtos de tecnologia assistiva. Disponível em <http://assistiva.mct.gov. br/catalogo>. Acesso em 12 de setembro de 2015.

CLARKSON, J. et al. Inclusive Design: Design for the Whole Population. UK: Springer Sicence \& Business Midia, 2003.

CONNEL, B.R. et al. The Principles of Universal Design (Version 2.0). The Center for Universal Design. Raleigh, NC: NC State University, 1997.

Direct Medical Supply. Disponível em <http://directmedicalofamerica.com/wordpress/sho p/writing-aids/easy-glide-writer/\#tab-description >.
Realização:

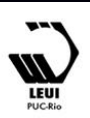




\section{$16^{\circ}$ \\ ERGODESIGN USIHC CINAHPA}

$16^{\circ}$ Ergodesign - Congresso Internacional de Ergonomia e Usabilidade de Interfaces Humano Tecnológica: Produto, Informações Ambientes Construídos e Transporte

$16^{\circ}$ USIHC - Congresso Internacional de Ergonomia e Usabilidade de Interfaces Humano Computador

CINAHPA | 2017 - Congresso Internacional de Ambientes Hipermídia para Aprendizagem.
Acesso em 31 de março de 2016

EAZYHOLD ${ }^{\mathrm{TM}}$. Disponível em <http://eazyhold. com/>. Acesso em 16 de outubro de 2015.

Enasco. Disponível em <https://www.enasco.com/ product/SN31905CQ/ > . Acesso em 11 de abril de 2016.

ESTEVES, A.C. et al. Força de preensão, lateralidade, sexo e características antropométricas da mão de crianças em idade escolar. Revista Brasileira de Cineantropometria e Desempenho Humano, Florianópolis, v. 7, n. 2, out. 2005.

Expansão Laboratório de Tecnologia Terapêutica. Disponível em <http://expansaolab.blogspot.com. br/2013/03/sala-de-recursos-multifuncionaisem.html>. Acesso em 25 de março de 2016.

GOMES FILHO, J. Design do objeto: bases conceituais. São Paulo: Estruturas, 2006.

INEP- Instituto Nacional de Estudos e Pesquisas Educacionais Anísio Teixeira Educação Inclusiva e o Atendimento Educacional Especializado.

Educação Inclusiva e o Atendimento

Educacional Especializado. 2011. Disponível em: <http://portal.inep.gov.br/web/educacenso/duv idas-educacao-especial>. Acesso em: 07 set. 2016.

Instituto Sabrina Belon. Disponível em $<$ http://www.sabrinabelon.org.br/index.php/tirapara-adaptacao-de-lapis.html>. Acesso em 25 de março de 2016.

Jetpens. Disponível em <http://www.jetpens.com/ Tombow-Ippo-Coiled-Pencil-Grip-Aid-Blue-Setof-4/pd/9656>. Acesso em 21 de maio de 2016.

LÖBACH, B. Design industrial: bases para a configuração dos produtos industriais. São Paulo: Edgard Blücher, 2001.

Maddak Sp Ableware. Disponível em < http:// www. maddak.com/ring-writer-clip-bag-of-p27903.html> e <http://www.maddak.com/thearthwriter-hand-aid-p-27899.html>. Acesso em 23 de março de 2016.
MARCELINO, J. R. Q.: MARTINS, L. B.; ARAÚJO, K.M. Design Inclusivo: Ensaio. In: Congresso Brasileiro de Ergonomia, 18, 2016, Belo Horizonte. Anais...

MARCELINO, J. R. Q.: MARTINS, L. B. Parâmetros e requisitos para e projeto de artefatos para a atividade de desenho da criança com paralisia cerebral. Ergodesign \& HCL, Rio de Janeiro-Brasil, v. 3, n. 3, ano 3, p. 64-71, 2015.

MN Suprimentos. Disponível em $<$ http://www. mnsuprimentos.com.br/menu/?p=658>. Acesso em 10 de setembro de 2015 .

MORAES; MONT'ALVÃO. Ergonomia, conceitos e aplicações. $3^{\mathrm{a}}$ ed. Rio de Janeiro: iuser, 2003.

MUNARI, B. Das coisas nascem coisas. São Paulo: Martins Fontes, 1981.

My Diffability. Disponível em $<$ http://www.mydiffability.com.au/products/ringpen-ultra $>$. Acesso em 11 de abril de 2016

SASSAKI, K. S. Escola da gente. Disponível em $<$ http://www.escoladegente.org.br /terminologia .php>. Acesso em 29 de fevereiro de 2016

School especialty. Disponível em <https://store.schoolspecialty.com/OA_HTML/ibe CCtpItmDspRte.jsp?minisite $=10206 \&$ item $=18817$ 22>. Acesso em 01 de abril de 2016

Writing Assistive Technologies For Reluctant Writers. Disponível em <http://watreluctantwriters. blogspot.com.br/2012/07/low-techassistive-

technology.html >. Acesso em 02 de outubro de 2015.

\section{Agradecimentos}

Agradecemos aos órgãos de fomento pela realização do PIBIC e do Projeto de Extensão. Nossa gratidão também aos educadores da Cidade do Recife e aos estudantes de Design por terem contribuído enquanto voluntários.
Realização:

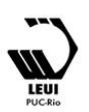

